\title{
Expression profiling and identification of potential molecular targets for therapy in pulmonary large-cell neuroendocrine carcinoma
}

\author{
AKIRA IYODA ${ }^{1}$, WILLIAM D. TRAVIS ${ }^{2}$, INDERPAL S. SARKARIA ${ }^{3}$, SHI-XU JIANG $^{4}$, HIDEKI AMANO ${ }^{1}$, \\ YUICHI SATO ${ }^{5}$, MAKOTO SAEGUSA ${ }^{4}$, VALERIE W. RUSCH ${ }^{3}$ and YUKITOSHI SATOH ${ }^{1}$
}

\author{
${ }^{1}$ Department of Thoracic Surgery, Kitasato University, School of Medicine, Kanagawa, Japan; Departments of ${ }^{2}$ Pathology, and \\ ${ }^{3}$ Surgery, Thoracic Service, Memorial Sloan-Kettering Cancer Center, New York, NY, USA; Departments of ${ }^{4}$ Pathology, \\ and ${ }^{5}$ Applied Tumor Pathology, Graduate School of Medical Sciences, Kitasato University, Kanagawa, Japan
}

Received June 22, 2011; Accepted July 29, 2011

DOI: 10.3892/etm.2011.343

\begin{abstract}
The prognosis for patients with large-cell neuroendocrine carcinoma (LCNEC) of the lung is extremely poor, and an optimal treatment has not yet been established. It has been recently reported that molecular-targeted therapies, such as tyrosine kinase inhibitors for epidermal growth factor receptor (EGFR), are effective in patients with lung carcinoma. In efforts to improve the prognosis of patients with LCNEC, we analyzed gene expression, gene mutations and immunohistochemical (IHC) expression of known molecular targets in LCNECs, and compared the expression to that of lung adenocarcinomas (ACs). Thirteen patients with primary LCNEC and 14 patients with AC were analyzed. We evaluated IHC expression for c-KIT, human epidermal growth factor receptor type 2(HER2) and vascular endothelial growth factor (VEGF), gene mutations for EGFR, K-ras and c-kit, and gene expression using fluorescence in situ hybridization for EGFR. In cases with LCNEC, the IHC expression of c-KIT, HER2 and VEGF was $76.9,30.8$ and $100 \%$, respectively. There was a significant difference in the IHC expression of c-KIT and HER 2 between the LCNEC and AC cases. Two cases of LCNEC had overexpression of HER2, and the frequency of EGFR gene mutations was higher in the the AC group, with only a single EGFR mutation (exon 18) identified in the LCNEC group. Although LCNEC had a higher rate of expression of c-KIT by IHC, no c-kit gene mutations were found. These findings suggest a potential role for anti-VEGF-, anti-cKIT- and possibly anti-HER2-targeted agents in the treatment of LCNEC.
\end{abstract}

Correspondence to: Dr Akira Iyoda, Department of Thoracic Surgery, Kitasato University, School of Medicine, 1-15-1 Kitasato, Minamiku, Sagamihara, Kanagawa 252-0374, Japan

E-mail: aiyoda@med.kitasato-u.ac.jp

Key words: large-cell neuroendocrine carcinoma, moleculartargeted therapy, vascular endothelial growth factor, c-KIT, human epidermal growth factor receptor type 2

\section{Introduction}

Large-cell neuroendocrine carcinomas (LCNEC) of the lung are aggressive tumors exhibiting features of high-grade neuroendocrine tumors, a poor clinical prognosis and a biological behavior similar to that of small-cell lung carcinomas (SCLCs) (1-3). However, the treatment of patients with LCNEC has traditionally been based on that of non-small cell lung carcinomas (NSCLCs). To improve the prognosis of patients with LCNEC, understanding the clinicopathological features and the effectiveness of treatment in patients with LCNEC is imperative. Recent reports have revealed the effectiveness of molecular-targeted therapy in patients with lung adenocarcinoma (AC) $(4,5)$. Epidermal growth factor receptor (EGFR)-tyrosine kinase inhibitor (TKI) has been effective for NSCLC, particularly in patients with lung AC and specific EGFR mutations in exon 19 or exon 21, or Asian patients (4). The EGFR mutation status can be used as a good predictor of the clinical benefit of EGFR-TKI (6). On the other hand, angiogenesis is also one of the hallmarks of cancer (7). Vascular endothelial growth factor (VEGF) is an important regulator of angiogenesis, and inhibition of VEGF has demonstrated survival benefits for patients with colorectal cancers (8). The expression of VEGF may also be related to prognosis in NSCLC (9), with monoclonal anti-VEGF antibody therapy showing a potential survival benefit in these patients (10).

Overexpression of the human epidermal growth factor receptor 2 (HER2) tyrosine kinase, usually due to over-amplification, has been linked to poor prognosis in breast cancer (11). Treatment with recombinant monoclonal anti-HER2 antibody (trastuzumab) displays activity in patients with breast cancer, particularly with high HER2 expression. A type III tyrosine kinase (KIT) is encoded by proto-oncogene c-kit, and exhibits high expression rates in gastrointestinal stromal tumors (12). The small-molecule tyrosine-kinase inhibitor imatinib is active against the intracellular ABL kinase, the chimeric BCR-ABL fusion oncoprotein of chronic myeloid leukemia, the transmembrane receptor KIT and platelet-derived growth factor receptors. Exposure of tumor cells dependent on the KIT pathway to imatinib blocks the kinase activity of KIT, 
arrests proliferation and causes apoptotic cell death (13). Imatinib has shown a high responsive rate in gastrointestinal stromal tumors, a tumor otherwise refractory to conventional chemoradiation therapy $(13,14)$.

Little is currently known regarding expression of these markers in LCNEC, or the use of their corresponding targetspecific therapies in patients with these tumors. In this study, we report the gene expression and mutation analyses of LCNEC, and discuss the possibility of molecular-targeted therapy in the management of patients with LCNEC.

\section{Patients and methods}

We analyzed 13 tumors resected at the Kitasato University Hospital and diagnosed as LCNEC according to the WHO classification (1). Immunohistochemical (IHC) staining was performed using a polyclonal anti-chromogranin A antibody (Dako, Glostrup, Denmark), a polyclonal anti-synaptophysin antibody (Dako) and an anti-neural cell adhesion molecule (NCAM) antibody (Nippon Kayaku, Tokyo, Japan). Neuroendocrine differentiation was identified by positive IHC staining for chromogranin A, synaptophysin or NCAM (1).

In cases of combined LCNEC, the histological components of LCNEC were selected according to microscopic findings to perform analyses of IHC expression, gene expression or gene mutation. Additionally, we analyzed 14 consecutive patients with ACs as a comparative cohort. The Institutional Review Board of the Kitasato University Hospital approved the protocols and procedures (B08-32).

\section{Expression and gene mutations of molecular markers}

IHC analyses. IHC analyses of c-KIT, HER 2 and VEGF were performed with anti-c-KIT (Dako, Tokyo, Japan), anti-HER2 (Dako) and anti-VEGF antibodies (Santa Cruz Biotechnology, Inc., Santa Cruz, CA, USA). The expression of HER2 was evaluated according to a previous study (15). Overexpression was indicated by a score of $3+$ or $2+$, and weak expression by a score of 1+. Representative stains are shown in Figs. 1-3.

EGFR gene mutation analysis. H\&E-stained sections of formalin-fixed paraffin-embedded tissues were reviewed to identify regions of tissue composed of tumor cells. Genomic DNA was isolated using the QIAamp DNA Mini kit (Qiagen, Hilden, Germany) according to the manufacturer's instructions. DNA extraction was identical for all mutation analyses. Exon sequences for EGFR (kinase domain) were amplified with specific primers by polymerase chain reaction (PCR). Molecularly pre-typed samples were selected based on results from direct DNA sequencing of EGFR (exons 18, 19, 20 and 21) (Fig. 4).

K-ras gene mutation analysis. After DNA isolation, exon 2 of the K-ras gene was amplified by PCR using TaKaRa Ex Taq Hot Start Version (Takara Bio Inc., Otsu, Japan) with forward primer 5'-GTGTGACATGTTCTAATATAGTCA-3' and reverse primer 5'-GTCCTGCACCAGTAATATGC-3'. The expected products of 209 base pairs were sequenced bidirectionally using the BigDye Terminator Cycle Sequencing kit (version 1.1; Applied Biosystems) and an ABI Genetic Analyzer (model 3100; Applied Biosystems) (Fig. 5).

c-kit gene mutation analysis. Exons 9,11, 13 and 17 of the c-kit gene were amplified by PCR using the following oligonucle-

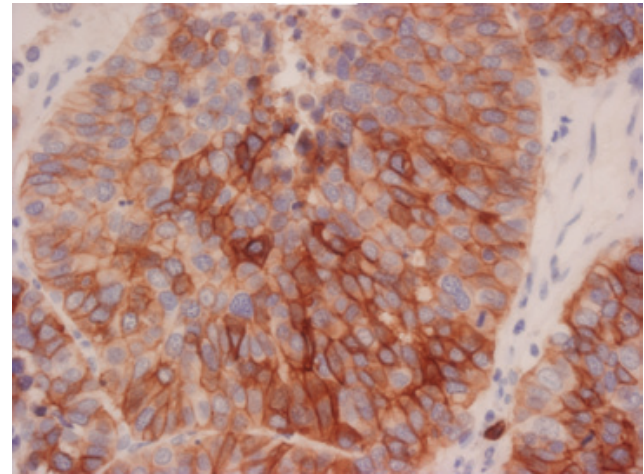

Figure 1. c-KIT expression in large-cell neuroendocrine carcinoma. Largecell neuroendocrine carcinoma displays positive expression of c-KIT by immunohistochemical staining.

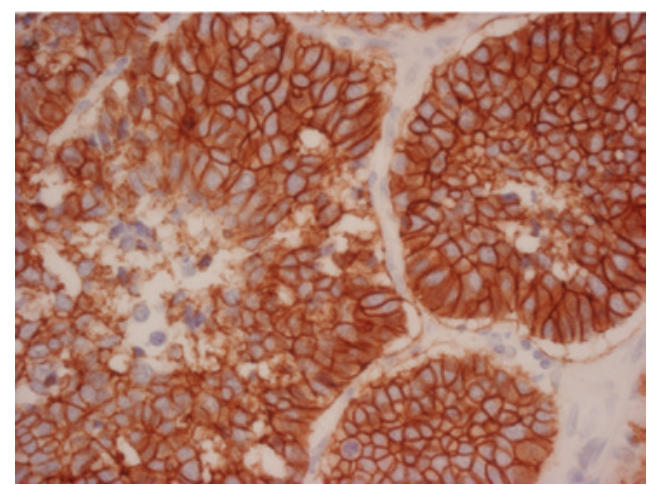

Figure 2. HER2 expression in large-cell neuroendocrine carcinoma. Largecell neuroendocrine carcinoma displays overexpression (3+) of HER2 by immunohistochemical staining.

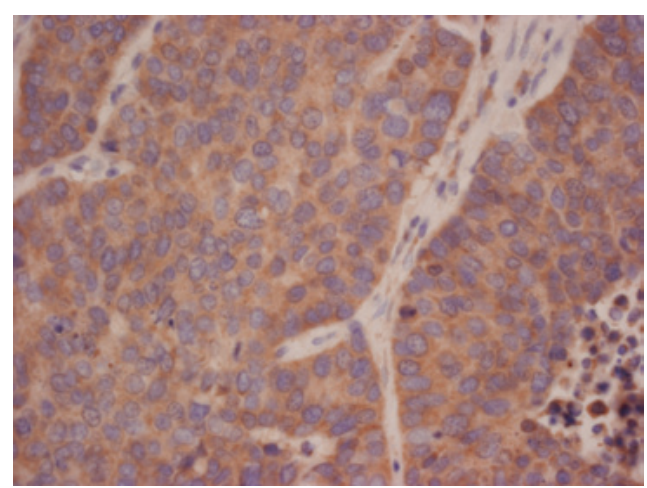

Figure 3. VEGF expression in large-cell neuroendocrine carcinoma. Largecell neuroendocrine carcinoma displays positive expression of VEGF by immunohistochemical staining.

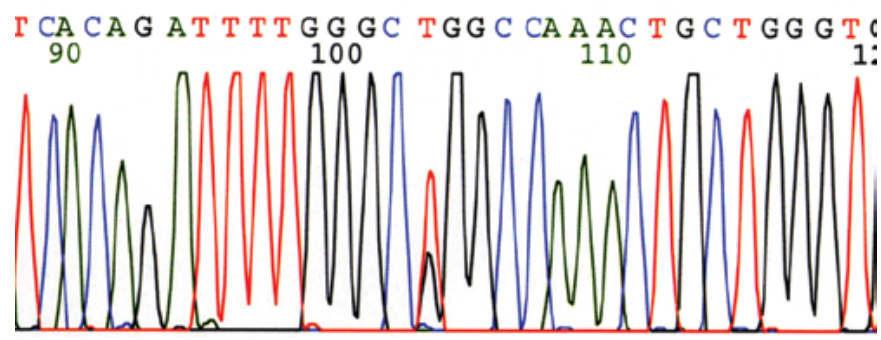

Figure 4. EGFR mutation in adenocarcinoma. Adenocarcinoma shows a point mutation of L858R of the EGFR gene (CTG to CGG). 


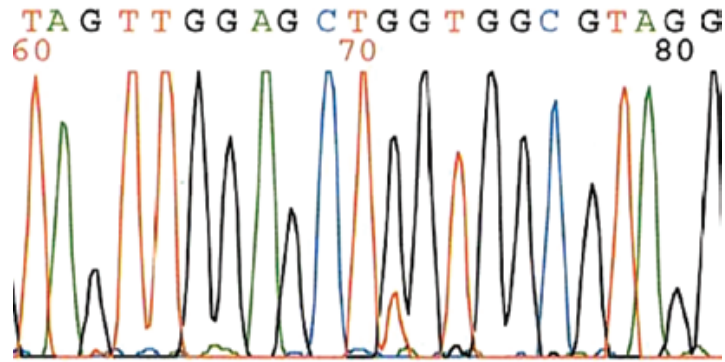

Figure 5. K-ras mutation in adenocarcinoma. Adenocarcinoma shows a point mutation of codon 12 of the K-ras gene (GGT to TGT).

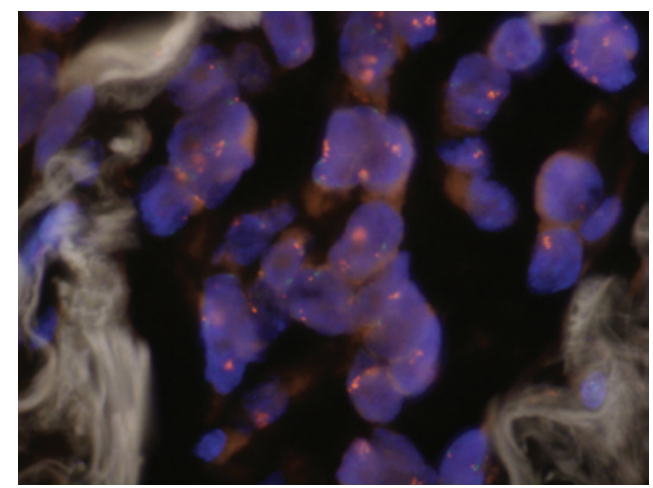

Figure 6. EGFR-FISH expression in adenocarcinoma. Adenocarcinoma shows an EGFR gene amplification with a 2.5 signal ratio.

otide primer pairs: for exon 9, 5'-TCCTAGAGTAAGCCAGGG CTT-3'/5'-TGGTAGACAGAGCCTAAACATCC-3'; for exon 11, 5'-GATCTATTTTTCCCTTTCTC-3'/5'-AGCCCC TGTTTCATACTGAC-3'; for exon 13, 5'-GCT TGA CAT CAG TTT GCC AG-3'/5'-AAA GGC AGC TTG GAC ACG GCT TTA-3'; for exon 17, 5'-CTCCTCCAACCTAATAG TGT-3'/5'-GTCAAGCAGAGAATGGGTAC-3'. The expected products were sequenced bidirectionally using the BigDye Terminator Cycle Sequencing kit (Applied Biosystems) and an ABI genetic analyzer (model 3100; Applied Biosystems) (16).

EGFR gene copy number analysis by FISH. EGFR gene copy number was evaluated by FISH using the LSI EGFR Dual Color probe (Abbott Molecular, Des Plaines, IL, USA) hybridized to the band region 7p12 in Spectrum Orange (EGFR DNA probe) and the centromere of chromosome 7 (7p11.1-q11.1, D7Z1 locus) in Spectrum Green (CEP7 DNA probe). We calculated $>60$ tumor cells, and evaluated a gene-to-chromosome
Table I. Patients characteristics of 13 cases of LCNEC and 14 cases of adenocarcinoma.

\begin{tabular}{lccc}
\hline Factor & $\begin{array}{c}\text { LCNEC } \\
(\mathrm{n}=13)\end{array}$ & $\begin{array}{c}\text { Adenocarcinoma } \\
(\mathrm{n}=14)\end{array}$ & $\mathrm{p}$-value \\
\hline Age & & & \\
$\quad$ Mean & 61.9 & 60.6 & 0.7356 \\
SD & 8.4 & 11.7 & \\
Gender & & & \\
$\quad$ Male & $11(84.6 \%)$ & $7(50.0 \%)$ & 0.1032 \\
Female & $2(15.4 \%)$ & $7(50.0 \%)$ & \\
Pathological stage & & & \\
I & $7(53.8 \%)$ & $8(57.1 \%)$ & 0.2091 \\
II & $0(0.0 \%)$ & $3(21.4 \%)$ & \\
III & $5(38.5 \%)$ & $3(21.4 \%)$ & \\
IV & $1(7.7 \%)$ & $0(0.0 \%)$ & \\
Smoking & & & \\
$\quad$ Smoker & $13(100 \%)$ & $7(50.0 \%)$ & 0.0058 \\
Non-smoker & $0(0.0 \%)$ & $7(50.0 \%)$ & \\
\hline
\end{tabular}

ratio per cell. The cut-off value was 2.0, and we estimated that tumor samples had a high EGFR gene copy number if a geneto-chromosome ratio per cell was $\geq 2.0$ (Fig. 6).

Statistical analysis. Fisher's exact test was used to compare binomial proportions. The $\chi^{2}$ test was used to assess differences in gender, pathological stage, smoking status, IHC positivity for c-KIT, HER 2 and VEGF, gene mutations for K-ras and EGFR, and FISH expression of the EGFR gene. The unpaired t-test was used to detect significant differences in patient age. A p-value $<0.05$ was considered statistically significant.

\section{Results}

There was no significant difference between patients with LCNEC and AC in relation to age, gender and pathological stage (Table I). There was a significant difference in smoking status (Table I).

Differential expression of study markers between LCNEC and $\mathrm{AC}$ are summarized in Table II. Markers with statistically significant differences in expression included c-KIT $(p=0.0018)$ and HER2 $(p=0.0037)$. The frequency of EGFR gene mutations was higher in the AC group $(\mathrm{p}=0.0128)$, with

Table II. Expression of molecular markers in all patients.

\begin{tabular}{|c|c|c|c|}
\hline Molecular marker & Positive cases (\%) of LCNEC & Positive cases (\%) of adenocarcinoma & $\mathrm{p}$-value \\
\hline c-KIT & $10(76.9)$ & $2(14.3)$ & 0.0018 \\
\hline HER2 & 2 (15.4) overexpression/2 (15.4) weak & $0(0)$ overexpression/11 (78.6) weak & 0.0037 \\
\hline VEGF & $13(100.0)$ & $13(92.9)$ & $>0.9999$ \\
\hline EGFR mutation & $1 \quad(7.7)$ & $8(57.1)$ & 0.0128 \\
\hline K-ras mutation & $0 \quad(0.0)$ & $2(14.3)$ & 0.4815 \\
\hline EGFR FISH & $0 \quad(0.0)$ & $2(14.3)$ & 0.4815 \\
\hline
\end{tabular}


only a single EGFR mutation [(a silent mutation in codon 725 (ACG to ACA) of exon 18)] identified in the LCNEC group. Only 2 cases of LCNEC had overexpression of HER2, and no cases of AC had overexpression of HER2.

For the LCNEC cases exhibiting expression of c-KIT, we analyzed gene mutations of c-kit. However, no case with the c-kit gene mutation was noted.

\section{Discussion}

Previous studies have reported poor prognosis for patients with LCNEC, with 5-year survival rates ranging from 15 to $57 \%(2,3)$. Tumor recurrence is frequent and problematic, and even patients with stage I disease show 5 -year survival rates of only $27-67 \%$.

The role of adjuvant therapy in this disease is not well understood. Studies of adjuvant therapy in LCNEC have been few, with small series of patients, although some have shown satisfactory response to chemotherapy (17).

Although molecular-targeted therapies for NSCLC, especially lung $\mathrm{AC}$, are increasingly investigated, there are no current reports of such therapies in LCNEC. This may be partly due to the fact that LCNEC was only recently officially recognized by the World Health Organization in 1999, and because of the rarity of this tumor. The purpose of the present study was to examine the expression of some of these known molecular targets of therapy in LCNEC.

EGFR mutations are frequently observed in lung AC. In the present study, we confirmed EGFR mutations in 57.1\% of ACs, but in only 1 [a silent mutation in codon 725 (ACG to ACA) of exon 18] of the 13 examined cases of LCNEC. Similarly, although previous reports have cited high EGFR copy number in ACs as predictive of response to EGFR-TKI therapy, no EGFR copy number expansion occurred in our LCNEC cohort as detected by FISH (18). Given these low rates of EGFR mutations (noted in exon 18) and normal gene copy number, we believe that EGFR-TKI is not likely to be an effective therapy for patients with LCNEC.

Previous studies have shown a survival benefit with the use of anti-angiogenic factors in NSCLC (10). In this study, LCNEC tumors frequently exhibited VEGF expression when compared to AC, suggesting a possible role for anti-VEGF therapy in the treatment of LCNEC. Further studies are warranted to investigate anti-VEGF therapies for this disease.

The effect of imatinib is largely predicted by the presence of activating c-kit mutations (19). While we identified high expression rates of c-KIT in patients with LCNEC compared to ACs, no c-kit mutations were identified in our LCNEC cohort. Given that c-KIT expression does not appear to correlate with the presence of an activating c-kit mutation, further investigation is required to determine what effectiveness KIT inhibitors may have in LCNEC.

In patients with breast carcinoma, the overexpression of HER2 is an important predictor for the response of trastuzumab (11). In this study, lung ACs had a significantly higher rate of HER 2 IHC staining than LCNEC, with only 2 LCNEC cases showing overexpression of HER2. Although the rates of overexpression of HER2 in LCNEC were not high, potentially the small percentage of patients with tumors showing strong HER2 expression may benefit by treatment with trastuzumab.
In summary, we carried out a preliminary molecular screening of putative targets of therapy for LCNEC. High expression rates of VEGF, comparable to that observed in lung ACs, support the further assessment of anti-VEGF therapies in these patients; studies concerning anti-VEGF therapies in LCNEC patients have not been reported to date. Likewise, strong expression of HER2 and c-KIT in a subset of these patients suggests possible roles for targeted therapies, such as trastuzumab and imatinib. Additional analyses are warranted to better elucidate treatment responses to imatinib in c-KIT-positive patients, even in the absence of a c-kit mutation. Finally, the infrequent presence of an EGFR mutation and increased gene copy number suggest a minimal role of EGFR-TKI therapy for LCNEC patients.

\section{Acknowledgements}

The authors thank Kenji Nezu, Fumihiro Ogawa, Yoshio Matsui and Naomi Kurouzu for the assistance in the preparation of the manuscript. This study was supported in part by a Grant-in-aid for Scientific research (C) 21591822 of the Japanese Ministry of Education, Culture, Sports, Science, and Technology.

\section{References}

1. Travis WD, Colby TV, Corrin B, Shimosato Y and Brambilla E: Histological Typing of Lung and Pleural Tumours. World Health Organization International Histological Classification of Tumors, XIII. 3rd edition. Springer-Verlag, Berlin/Heidelberg, 1999.

2. Iyoda A, Hiroshima K, Nakatani Y and Fujisawa T: Pulmonary large cell neuroendocrine carcinoma: its place in the spectrum of pulmonary carcinoma. Ann Thorac Surg 84: 702-707, 2007.

3. Iyoda A, Hiroshima K, Toyozaki T, Haga Y, Fujisawa T and Ohwada H: Clinical characterization of pulmonary large cell neuroendocrine carcinoma and large cell carcinoma with neuroendocrine morphology. Cancer 91: 1992-2000, 2001.

4. Takano T, Fukui T, Ohe Y, Tsuta K, Yamamoto S, Nokihara H, Yamamoto N, Sekine I, Kunitoh H, Furuta K and Tamura T: EGFR mutations predict survival benefit from gefitinib in patients with advanced lung adenocarcinoma: a historical comparison of patients treated before and after gefitinib approval in Japan. J Clin Oncol 26: 5589-5595, 2008.

5. Zhu CQ, da Cunha Santos G, Ding K, Sakurada A, Cutz JC, Liu N, Zhang T, Marrano P, Whitehead M, Squire JA, Kamel-Reid S, Seymour L, Shepherd FA and Tsao MS; National Cancer Institute of Canada Clinical Trials Group Study BR.21: Role of KRAS and EGFR as biomarkers of response to erlotinib in National Cancer Institute of Canada Clinical Trials Group Study BR.21. J Clin Oncol 26: 4268-4275, 2008.

6. Mitsudomi T, Kosaka T, Endoh H, Horio Y, Hida T, Mori S, Hatooka S, Shinoda M, Takahashi T and Yatabe Y: Mutations of the epidermal growth factor receptor gene predict prolonged survival after gefitinib treatment in patients with non-small-cell lung cancer with postoperative recurrence. J Clin Oncol 23: 2513-2520, 2005.

7. Hanahan D and Weinberg RA: The hallmarks of cancer. Cell 100: 57-70, 2000.

8. Hurwitz H, Fehrenbacher L, Novotny W, Cartwright T, Hainsworth J, Heim W, Berlin J, Baron A, Griffing S, Holmgren E, Ferrara N, Fyfe G, Rogers B, Ross R and Kabbinavar F: Bevacizumab plus irinotecan, fluorouracil, and leucovorin for metastatic colorectal cancer. N Engl J Med 350: 2335-2342, 2004.

9. Seto T, Higashiyama M, Funai H, Imamura F, Uematsu K, Seki N, Eguchi K, Yamanaka T and Ichinose Y: Prognostic value of expression of vascular endothelial growth factor and its flt-1 and KDR receptors in stage I non-small-cell lung cancer. Lung Cancer 53: 91-96, 2006.

10. Sandler A, Gray R, Perry MC, Brahmer J, Schiller JH, Dowlati A, Lilenbaum R and Johnson DH: Paclitaxel-carboplatin alone or with bevacizumab for non-small-cell lung cancer. N Engl J Med 355: 2542-2550, 2006. 
11. Lennon S, Barton C, Banken L, Gianni L, Marty M, Baselga J and Leyland-Jones B: Utility of serum HER2 extracellular domain assessment in clinical decision making: pooled analysis of four trials of trastuzumab in metastatic breast cancer. J Clin Oncol 27: 1685-1693, 2009.

12. Hirota S, Isozaki K, Moriyama Y, Hashimoto K, Nishida T, Ishiguro S, Kawano K, Hanada M, Kurata A, Takeda M, Muhammad Tunio G, Matsuzawa Y, Kanakura Y, Shinomura Y and Kitamura Y: Gain-of-function mutations of c-kit in human gastrointestinal stromal tumors. Science 279: 577-580, 1998.

13. Demetri GD, von Mehren M, Blanke CD, van den Abbeele AD, Eisenberg B, Roberts PJ, Heinrich MC, Tuveson DA, Singer S, Janicek M, Fletcher JA, Silverman SG, Silberman SL, Capdeville R, Kiese B, Peng B, Dimitrijevic S, Druker BJ, Corless C, Fletcher CD and Joensuu H: Efficacy and safety of imatinib mesylate in advanced gastrointestinal stromal tumors. N Engl J Med 347: 472-480, 2002.

14. Verweij J, Casali PG,Zalcberg J,LeCesne A, Reichardt P, Blay JY, Issels R, van Oosterom A, Hogendoorn PC, van Glabbeke M, Bertulli R and Judson I: Progression-free survival in gastrointestinal stromal tumours with high-dose imatinib: randomised trial. Lancet 364: 1127-1134, 2004.

15. Tsuda H, Akiyama F, Terasaki H, Hasegawa T, Kurosumi M, Shimadzu M, Yamamori S and Sakamoto G: Detection of HER-2/ neu (c-erb B-2) DNA amplification in primary breast carcinoma Interobserver reproducibility and correlation with immunohistochemical HER-2 overexpression. Cancer 92: 2965-2974, 2001.
16. Hirota S, Nishida T, Isozaki K, Taniguchi M, Nakamura J, Okazaki T and Kitamura Y: Gain-of-function mutation at the extracellular domain of KIT in gastrointestinal stromal tumours. J Pathol 193: 505-510, 2001.

17. Yamazaki S, Sekine I, Matsuno Y, Takei H, Yamamoto N, Kunitoh H, Ohe Y, Tamura T, Kodama T, Asamura H, Tsuchiya R and Saijo N: Clinical responses of large cell neuroendocrine carcinoma of the lung to cisplatin-based chemotherapy. Lung Cancer 49: 217-223, 2005.

18. Hirsch FR, Herbst RS, Olsen C, Chansky K, Crowley J, Kelly K, Franklin WA, Bunn PA Jr, Varella-Garcia M and Gandara DR: Increased EGFR gene copy number detected by fluorescent in situ hybridization predicts outcome in non-small-cell lung cancer patients treated with cetuximab and chemotherapy. J Clin Oncol 26: 3351-3357, 2008.

19. Heinrich MC, Owzar K, Corless CL, Hollis D, Borden EC, Fletcher CD, Ryan CW, von Mehren M, Blanke CD, Rankin C, Benjamin RS, Bramwell VH, Demetri GD, Bertagnolli MM and Fletcher JA: Correlation of kinase genotype and clinical outcome in the North American Intergroup Phase III Trial of imatinib mesylate for treatment of advanced gastrointestinal stromal tumor: CALGB 150105 Study by Cancer and Leukemia Group B and Southwest Oncology Group. J Clin Oncol 26: 5360-5367, 2008. 